\title{
Joint Investigation and 3D Visual Evaluation of Rock Mass Quality
}

\author{
Haiping Yuan, ${ }^{1}$ Chenghao Chen, ${ }^{1}$ Yixian Wang $\mathbb{D}^{1,2}$ Hanbing Bian, ${ }^{3}$ and Yan Liu ${ }^{2}$ \\ ${ }^{1}$ School of Civil Engineering, Hefei University of Technology, Hefei 230009, China \\ ${ }^{2}$ State Key Laboratory of Explosion Science and Technology, Beijing Institute of Technology, Beijing 100081, China \\ ${ }^{3}$ Laboratoire de Génie Civil et Géoenvironnement, Université de Lille, Lille 5900, France \\ Correspondence should be addressed to Yixian Wang; wangyixian2012@hfut.edu.cn
}

Received 1 May 2020; Revised 10 December 2020; Accepted 14 December 2020; Published 30 December 2020

Academic Editor: Jia-Rui Lin

Copyright (C) 2020 Haiping Yuan et al. This is an open access article distributed under the Creative Commons Attribution License, which permits unrestricted use, distribution, and reproduction in any medium, provided the original work is properly cited.

\begin{abstract}
In order to realize the high efficiency quality classification and three-dimensional visualization of engineering rock mass and to solve the technical difficulties of the traditional rock mass quality evaluation method such as high labor intensity, long process time consumption, many intervention processes such as scale measurement and manual calculation, and nonintuitive classification results, this paper puts forward a 3D visual rock mass quality evaluation method and system based on close-range photography, which optimizes the traditional rock mass quality evaluation method, makes the rock mass classification threedimensional and visible, and realizes the estimation of unrevealed rock mass quality evaluation index. The research results show the following: (1) The method of storing joint information by close-range photography and extracting joint information by human-computer interaction improves the working efficiency and the process is safe and controllable compared with the traditional method of collecting fracture parameters. (2) Based on the statistical analysis of 97 groups of roadway survey data, the comprehensive statistical regression formula between BQ value of Chinese national standard and RMR value is given, and there is a good correlation between BQ value and RMR value of rock mass quality index. (3) Based on the power-inverse ratio method, the three-dimensional model of rock mass classification of the mine was established, and the cutting model obtained the current distribution diagram of rock mass quality grade, providing scientific reference for drilling, blasting, support, and other production design optimizations.
\end{abstract}

\section{Introduction}

Gu Dezhen has established the concept of rock mass structure in the early 1960s [1]. It is suggested that the characteristics of rock mass mainly depend on the internal structure of rock mass $[2,3]$. Fine description, rapid measurement, and visual representation of the structure of rock mass and its spatial distribution of quality grade are the foundation and key to solve many underground engineering problems. Geological survey of traditional joints and fractures is complicated and cumbersome. The observation points are determined by the surveyor's line first, and then the joint measurement is carried out one by one on the site of the bad working environment by means of a scale and geological compass, and the data of the nature, occurrence, length, width and spacing of each joint fracture, and the position of the intersection point between the structure surface and the measuring line are recorded. It is obvious that the traditional collection methods with high labor intensity, low efficiency, high risk, and high accuracy affected by human and environmental factors need to be improved and innovated urgently. At present, there are many comprehensive evaluation methods of rock mass quality at home and abroad. The evaluation factors and evaluation criteria of grading methods of rock mass quality evaluation are different, and different evaluation methods for the same evaluation object may have different evaluation results $[4,5]$. Therefore, it is very important to study the correlation between different rock mass quality evaluation and grading methods. With the rapid development of science and technology, 3D imaging technology in the 21st century has shown significant development potential. The 3D classification of rock mass quality will guide engineering construction more intuitively and concretely, which is the development trend of rock mass quality classification. 
The method of manual field contact measurement [6-10] usually uses geological compass, geological hammer, measuring rope, tape gauge, and other tools to investigate and measure joints and fractures one by one. The accuracy of this method is greatly influenced by human and environmental factors, which is time-consuming, laborious, and inefficient, and the proportion of labor cost is high. Normally, 200-300 fractures can be measured in pairs a day. Fracture information collectors have long been exposed to the field environment, affected by weather, section exposure, and other environmental factors, and sometimes may be threatened by geological disasters such as landslides. Borehole survey is an important part of geophysical logging technology. This method has special requirements for drilling technology and quality, and the interpretation accuracy is sometimes difficult to guarantee. Though the ANN (Artificial Neural Network) combined with fuzzy logic [11] and RMD index [12] is used to study the distribution of fracture density, it is still difficult to reflect the characteristics of structural anisotropy of rock mass. And the method is not suitable for obtaining and collecting the profile information in large quantities. Photogrammetry is a technique to reconstruct the space position and three-dimensional shape of the object by using the image of the subject, and its history is comparable to that of photographs, dating back to the mid-19th century (Ross-Brown and Atkinson, 1972 [13]). Compared with other methods, the digital image of field rock is obtained by digital camera equipment, and then image processing is carried out by computer, and the relevant fracture data can be obtained. This method can transfer a large number of field works to the indoor to complete, with the advantages of precision, high efficiency, practicality, comprehension, and few environmental disturbances, which effectively solve the disadvantages and shortcomings of the traditional method, provide a new idea for obtaining geometric information of rock mass structure surface, and have been favored by the majority of scholars [14-19]. Wu [20] introduced the information processing scheme of digital image of beach rock mass developed according to modern computer vision theory; Fan [21] studied the intelligent recognition of digital images of rock mass fractures based on image processing and recognition technology to realize automatic interpretation of fractures; Li et al. [22] realized the evaluation of radial differences and axial prediction of tunnel rock mass structure based on the sequence palm surface image and then realized the effective agreement between the quantitative index of rock mass structure and the engineering purpose; Galdames et al. [23] classified and processed segmented rock images using hyperspectral sensors, laser range finders, and color cameras.

The early rock mass classification methods were proposed based on the experience of tunnel engineering with shallow buried depth, such as Protodyakonov classification method, Terzaghi classification method, and RMR classification method (Method of Rock Mass Rating). At present, the development trend of surrounding rock classification method is from qualitative-based classification method to qualitative-quantitative combination method. Moreover, the classification index has been developed from single index to multi-index evaluation system. The most widely influential methods are BQ method (Chinese standard for engineering classification of rock mass), $Q$ system classification, and RMR classification method. With the development of human engineering technology and the requirement of modern engineering, more and more deep-buried extra-long tunnels are needed. The geological conditions of these tunnels are often complex and the crustal stress conditions are prominent, while the early methods have less consideration on the influence of crustal stress, especially high ground stress, on tunnel stability, which limits their application in modern tunnel design. Tan [24] modified the traditional $Q$ system method and established a method suitable for the evaluation of surrounding rock quality in deep engineering, based on the influence of high ground stress, high temperature, and high osmosis on surrounding rock quality. RMR method did not consider the effect of crustal stress or groundwater on the stability of rock mass and supporting structure [25]. Since both RMR and $Q$ systems use RQD (rock quality designation) value as basic parameters, the defects in the description of joint state by the values themselves inevitably lead to the deviation of the final rock mass quality score. Chen et al. [26] researched on three-dimensional accurate division method of structural homogenization in underground mines for the problems of weak detailed identification ability of existing homogenization methods; $\mathrm{Su}$ and Ning [27] used the maximum interval classifier to judge the surrounding rock level; Cong et al. [28] considered the influence of tunnel span on the stability of surrounding rock, adjusting and improving the basic quality index of surrounding rock, so that the quantitative and qualitative classification results of surrounding rock are basically consistent. At present, the research and improvement of rock mass quality evaluation by researchers at home and abroad mainly focus on these directions, such as the research and development of special measuring equipment and supporting procedures, the improvement or supplement of classical rock mass quality evaluation methods, and the simple development of rock mass quality rating procedures. However, there is less research on the method of intervention in rock mass investigation by simple, fast, efficient, and economical ordinary photographic camera suitable for engineering.

Driven by new theories and technologies such as big data, cloud computing, artificial intelligence, and the strong demand of economic and social development, big data driving knowledge learning, cross-media collaborative processing, man-machine collaborative enhancing intelligence, and other aspects have become the focus and hot spot of geotechnical engineering development. It is a matter of great urgency to innovate the traditional low efficiency technology means and solve the multidisciplinary and common problems of fine description, rapid measurement, and visual representation of rock mass structure and its quality grade. In order to improve the geological survey of traditional joints and fractures, to realize the high efficiency automation and $3 \mathrm{D}$ visualization of rock mass quality classification, the fracture photos are obtained by closerange photography [29-33], and the key characteristic 
parameters of joint fractures are extracted by computer processing. According to all kinds of published documents related to rock mass quality classification and interconversion of basic parameters for quality classification of rock mass, the rock mass quality classification is completed quickly. At the same time, a program automatically processes the collected basic information and directly gives the rock mass quality evaluation results of each set of information according to the relevant classification methods. The correlation between RMR and BQ is analyzed and discussed on the basis of engineering example [34-36]. Finally, a threedimensional model of rock mass classification is established based on the distance power-inverse ratio method. The research idea is shown in Figure 1. On the basis of MATLAB platform, the intelligent evaluation system of image fracture AI identification and rock mass quality is developed, the quality grade of rock mass and the dynamic distribution of regional rock mass under mining disturbance are finely described, rapidly measured, and directly visualized, and the digital, intelligent transition and 3D visual management of quantification of rock mass and rock mass quality identification are realized.

\section{Basic Information Acquisition of Rock Mass Quality Classification}

2.1. Close-Up Photo Collection of Joints and Cracks. The close-up photography is used to collect the joint fissure images of the rock mass in the small area. The quality of the collected photographs is affected by factors such as lighting, shooting distance, shooting angle, and surrounding environment. Therefore, the specified parameters are uniformly adopted for the controllable factors. Combining with the field situation, four Dongzhisheng DS-900 LED bulbs are used as light sources; each bulb has a maximum luminous flux of 2000 LM and a light source of scattering light. To ensure a moderate light intensity, the linear distance between the bulb and the outcropping plane of joint cracks should be 1 2 meters, and the same shooting distance should be 1 2 meters. Degree will result in different scales in different areas of the image. In order to ensure the same scales in different parts of the image, we should try to ensure that the lens plane is parallel to the rock wall plane. Lighting arrangement adopts the way of 45 degrees angle between the lamp position and the outcrop plane of joints and fissures. The plane of joints and fissures is often uneven, so the upper and lower left sides of the camera should be arranged as far as possible. A lamp position is arranged in the four directions of the upper right and the lower right, as shown in Figure 2. In order to determine the scale of the close-up photographic photograph, a reference object of a known regular shape of the sheet is placed at a position within the photographing area and does not affect the integrity of the joint fissure; a sheet-like reference object, a photographic area plane, and a camera lens should be in a parallel state to avoid scale deviation, photographic photos shown in Figure 3.

The close-range photographs obtained by this method have soft and uniform light and clear joints.
2.2. Collection of Rock Strength Indicators. Strength of rock generally includes compressive strength (uniaxial compressive strength and triaxial compressive strength), tensile strength, and shear strength, among which shear strength and compressive strength are often the main factors to determine the stability of rock engineering. This paper uses a portable point loader to measure the compressive strength of rock; the rock sample after destruction is shown in Figure 4; at the anchor point of each close-up photography, no less than 12 rock samples are taken and the sampling point sampling position is recorded, and the uniaxial compressive strength of the rock is obtained according to the following equation [37]:

$$
R_{\mathrm{c}}=22.82 I_{\mathrm{s}}^{0.75} \text {. }
$$

2.3. Engineering Factors Affecting Rock Mass Strength. The basic quality of rock mass is the inherent characteristic of rock mass, which reflects the most basic mechanical properties of rock mass. Based on the actual project of a metal mine in south China, the rock mass quality is classified according to the rock mass quality evaluation method, and the information such as the strike inclination angle, structural surface conditions, groundwater conditions, and field coordinates of the dominant joint group at the close shot should be collected in the field. In this paper, roadway investigation and statistical analysis are carried out in the range of $-540 \mathrm{~m} \sim-455 \mathrm{~m}$ in a metal mine in south China, 97 joint pictures and 97 groups of corresponding index data are obtained, and a total of 6048 fractures and related parameters are obtained. Information collection of engineering factors affecting rock mass strength is shown in Table 1. The structure surface conditions A, B, C, D, and E, respectively, mean "discontinuous, closed, very rough, and the unweathered rock cliff," " $<1 \mathrm{~mm}$, slightly rough wall, width slightly weathered rock," " $<1 \mathrm{~mm}$, slightly rough wall, width serious weathering rock," "surface smooth or soft interlayer thickness $<5 \mathrm{~mm}$, the width of $1 \sim 5 \mathrm{~mm}$, continuous," "surface smooth or soft interlayer thickness $>5 \mathrm{~mm}$ or opening $>5 \mathrm{~mm}$, continuous." The groundwater conditions A, B, C, D, and E, respectively, mean "completely dry," "wet," "wet cave wall," "dripping water," and "running water."

After the on-site statistical data are recorded in this form, the rock mass quality information database on the computer side is input uniformly for storage and retention (the information database on the computer side has been made into a software form that can be dynamically changed at any time), paving the way for the automatic rock mass quality classification calculation by the self-programmed program later. This form of data statistics can be supplemented or deleted at any point in the mine and can change a single piece of data in the data group, thus realizing the dynamic grading of rock mass quality in the mine.

\section{Basic Information-Related Processing and Rock Mass Quality Classification}

3.1. Extraction of Crack Information in Close-Up Photographs. The geological survey of traditional joint fissures is mainly carried out by measuring personnel to determine the 


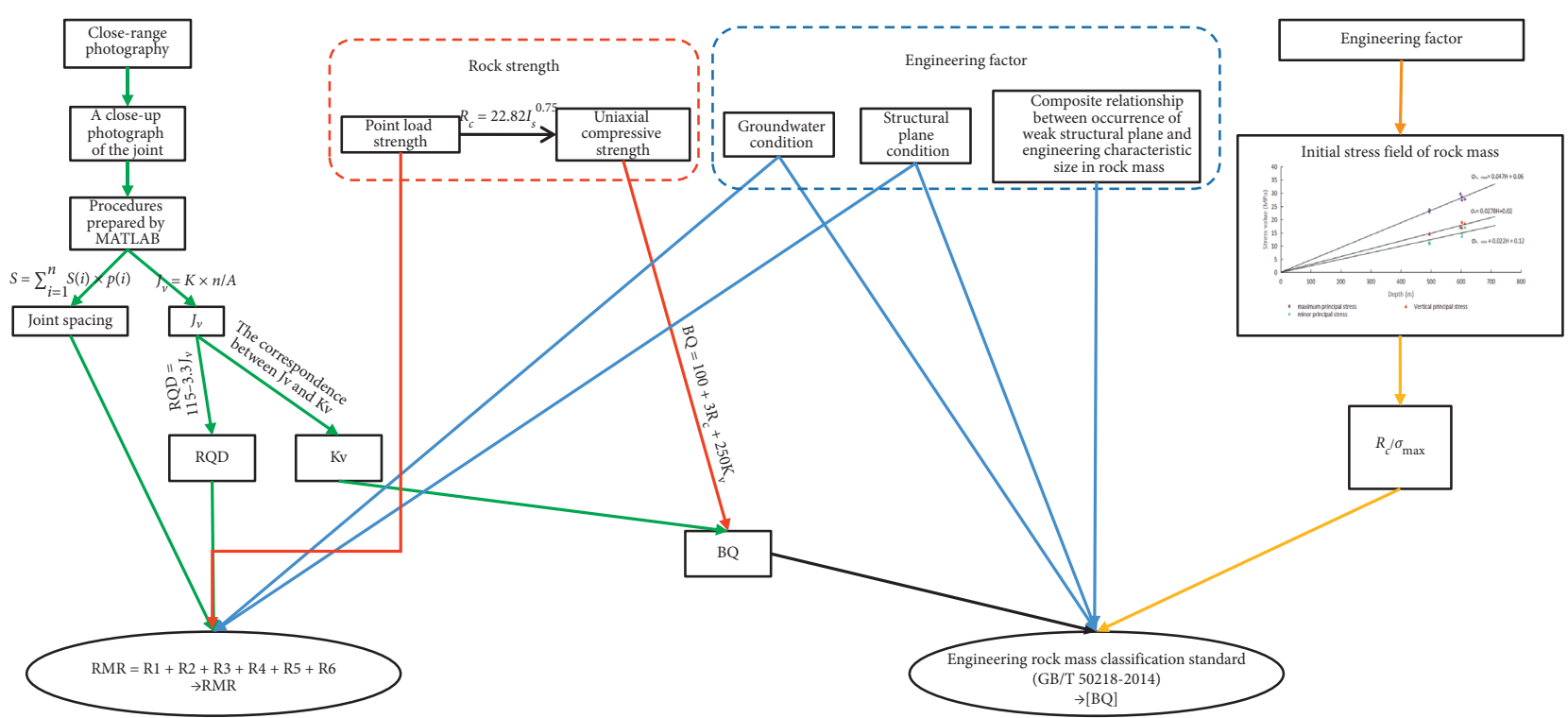

(a)

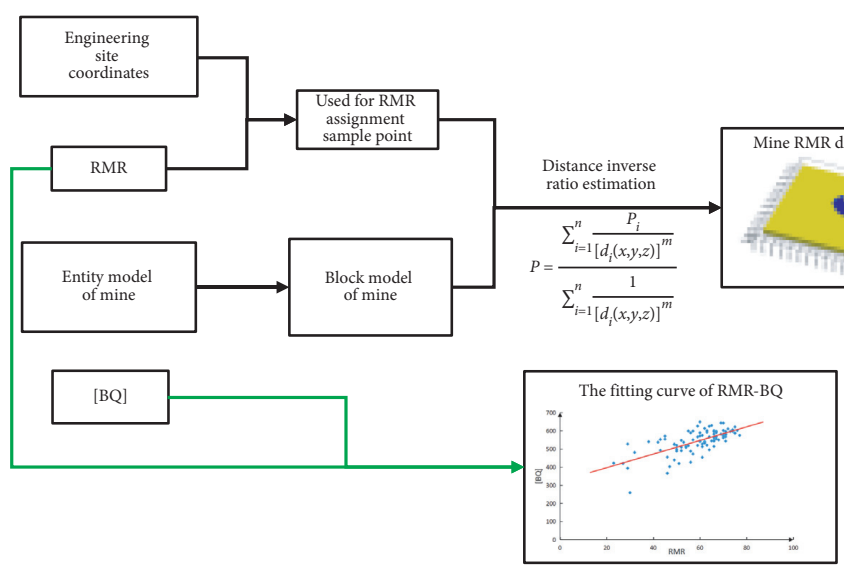

(b)

Figure 1: Overview of 3D visual rock mass quality evaluation method and system based on close-up photography: (a) the first part and (b) the second part.

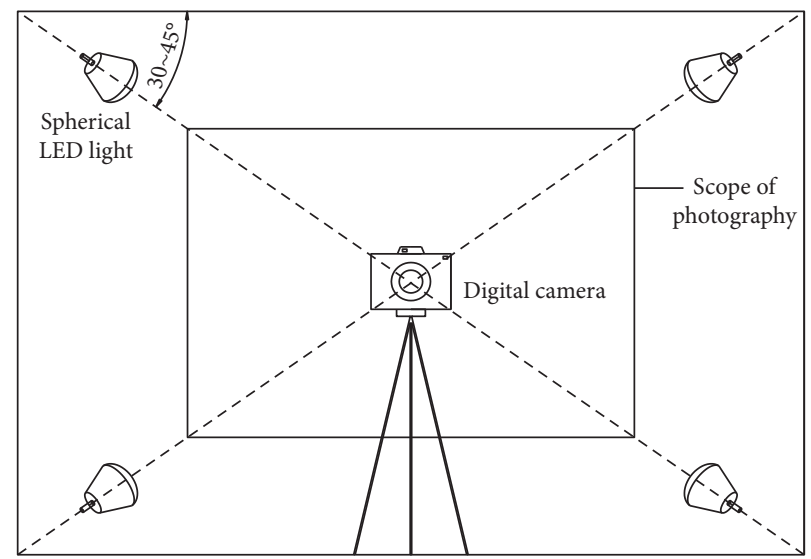

FIgURE 2: Schematic diagram of light source layout.

observation points, then manually measuring the nature, occurrence, and trace of each joint fissure by means of a tape measure, geological compass, and other tools on the site of the harsh working environment. Data such as length, width, spacing, structural plane, and intersection position of the survey line are summarized and entered into the Joint 


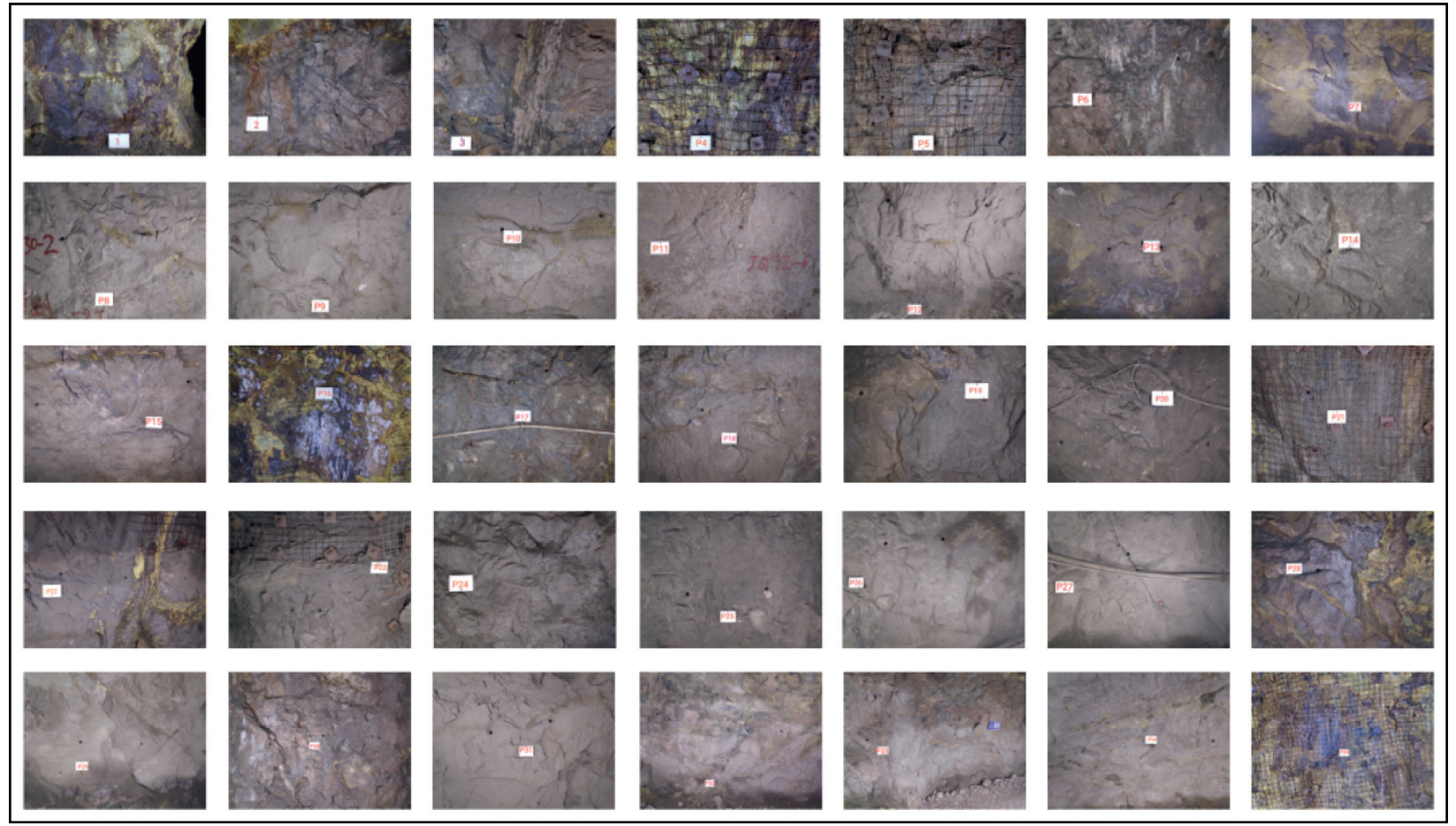

Figure 3: Close shot photography of joints and cracks.


FIgURE 4: Site point load test after rock damage.

Fracture Information Statistics Table. It is urgent to improve and innovate the traditional collection method, which is characterized by high labor intensity, low efficiency, high risk, and high accuracy under the influence of human and environmental factors. This paper processes the close-up photographs of the joints and cracks on the computer through self-programming and identifies and obtains the basic information of each fissure.

In this paper, the self-compiled MATLAB program is used to obtain the pixel-length scale $(\mathrm{cm} / \mathrm{pixel})$ of the photos by selecting the flaky reference objects in each close-up photography picture. Click the two end points of the crack to read the coordinate values of the two end points from the current coordinate system. According to the coordinates of the two end points and the scale, the centroid coordinates, length, and inclination angle of the crack can be obtained. However, for different ranges within the close-up photography digital image, the scale is deviated and needs to be corrected.

As shown in Figure 5, the length and width of the shooting plane area $A B C D$ are, respectively $a, b$, and the linear distance from the lens $O$ to the shooting plane area $A B C D\left|O O^{\prime}\right|=L$, where $O^{\prime}((1 / 2) a,(1 / 2) b)$ is the shooting 


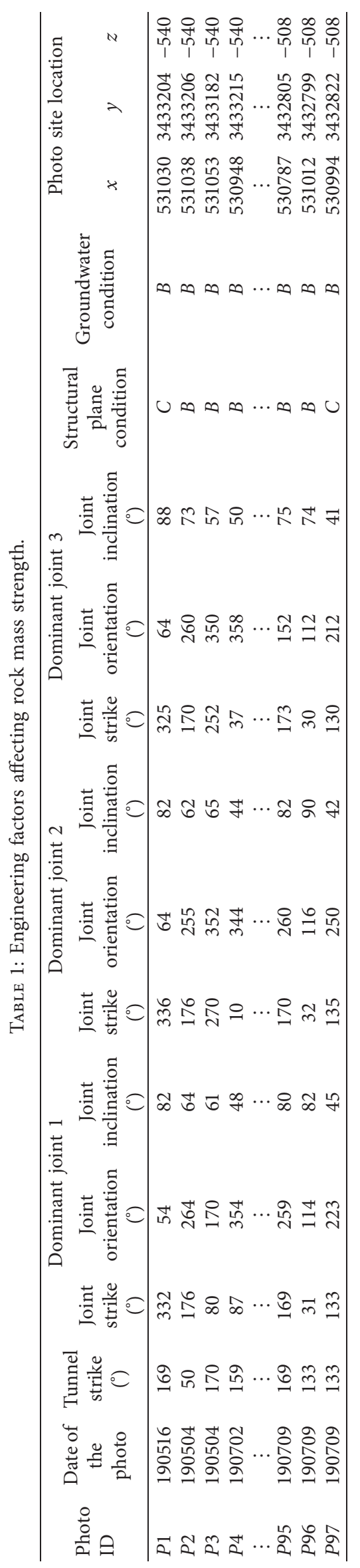






FIGURE 5: Schematic diagram of scale deviation correction.

plane area $A B C D$ center point, the center point of the reference object is $E\left(x_{1}, y_{1}\right)$, and the point $P\left(x_{i}, y_{i}\right)$ is any point in the shooting plane area $A B C D$; then, the line segment $O^{\prime} E$ and the line segment $O^{\prime} P$ length are shown in the following equations:

$$
\begin{aligned}
& \left|O^{\prime} E\right|=\sqrt{\left(x_{1}-\frac{a}{2}\right)^{2}+\left(y_{1}-\frac{b}{2}\right)^{2}}, \\
& \left|O^{\prime} P\right|=\sqrt{\left(x_{i}-\frac{a}{2}\right)^{2}+\left(y_{i}-\frac{b}{2}\right)^{2}} .
\end{aligned}
$$

Assuming that the standard scale $\lambda$ is taken at $\mathrm{O}^{\prime}$ point along the $O O^{\prime}$ direction, the scale $\lambda_{E}$ at the reference object should be corrected by the correction coefficient $k_{1}$; that is, $\lambda_{E}=k_{1} \lambda$, and $\lambda=\lambda_{E} / k 1$, as shown in the following equation:

$$
\lambda=\left(\frac{\lambda_{E}}{k_{1}}\right)=\lambda_{E} \frac{L}{\sqrt{\left(x_{1}-(a / 2)\right)^{2}+\left(y_{1}-(b / 2)\right)^{2}+L^{2}}} .
$$

When shooting at point $P$, the scale $\lambda_{P}$ should be multiplied by the correction factor $k_{2}$, and the scale $\lambda$ at point $P$ is as shown in the following equation:

$$
\lambda_{P}=k_{2} \lambda=\frac{\sqrt{\left(x_{i}-(a / 2)\right)^{2}+\left(y_{i}-(b / 2)\right)^{2}+L^{2}}}{L} \lambda .
$$

The following equation can be obtained from (4) and (5):

$$
\lambda_{P}=\frac{\sqrt{\left(x_{i}-(a / 2)\right)^{2}+\left(y_{i}-(b / 2)\right)^{2}+L^{2}}}{\sqrt{\left(x_{1}-(a / 2)\right)^{2}+\left(y_{1}-(b / 2)\right)^{2}+L^{2}}} \lambda_{E} .
$$

That is, $\lambda_{P}=K \lambda_{E}$, and using $K$ to correct the scale when the coordinates of any point in the photo $P\left(x_{i}, y_{i}\right)$ are obtained, the results are shown in Table 2 .

The spacing of two fractures can be calculated by using the coordinate of fracture endpoint (if the fractures do not intersect, the trapezoidal shape of the quadrangle of the fracture endpoint is approximately used to calculate the spacing; if fracture intersection exists, use the centroid distance as the crack spacing), single photo within group according to the angle of joints, and average of two adjacent fracture spacing in the group as a group of crack spacing; take fissure number that accounts for more than $10 \%$ of the total number of single photo fissures for effective group, on the basis of effective crack spacing $S(i)$ according to the weight $P(i)$ photos total distance $S$, as shown in the following equation. Manual review of 20 groups of fissure spacing was conducted, and the results are shown in Table 3. The results show that the error rate of fissure spacing calculated by fissure endpoint coordinates is less than $15 \%$ :

$$
S=\sum_{i=1}^{n} S(i) \times P(i)
$$

3.2. Index of Rock Mass Incompleteness. The strength of rock mass is significantly different from that of rock. The strength of rock mass is lower than that of rock, and only in a few cases is the strength of rock mass close to that of rock. The reason for this difference is that there are many large-scale structural planes and weak interlayers in rock mass. In engineering practice, rock mass is generally classified according to various specifications, and then parameters such as bearing capacity are selected correspondingly according to the quality classification. Rock mass incompleteness index generally refers to volume joint number $J_{v}$, rock quality designation $\mathrm{RQD}$, and rock mass integrity index $K_{v}$. It is an index reflecting the number and scale of various structural planes and weak interlayers in rock mass and has an important impact on rock mass quality.

3.2.1. Volume Joint Number $J_{v}$. The joint number of rock mass volumes is the number of structural planes per cubic meter of rock mass volume. The $J_{v}$ value calculated by Spacing Method should be calculated according to joint 
TABLE 2: Crack parameters in close-up photographs.

\begin{tabular}{lccccccccc}
\hline $\begin{array}{l}\text { Photo } \\
\text { ID }\end{array}$ & $\begin{array}{c}\text { Joint } \\
\text { ID }\end{array}$ & Centroid $x$ & Centroid $y$ & $\begin{array}{c}\text { Joint length } \\
(\mathrm{cm})\end{array}$ & $\begin{array}{c}\text { Joint dip } \\
\text { angle }\left(^{\circ}\right)\end{array}$ & $\begin{array}{c}\text { Left endpoint } \\
X \text { of line } \\
\text { segment }\end{array}$ & $\begin{array}{c}\text { Left endpoint } \\
Y \text { of line } \\
\text { segment }\end{array}$ & $\begin{array}{c}\text { Right } \\
\text { endpoint } X \text { of } \\
\text { line segment }\end{array}$ & $\begin{array}{c}\text { Right } \\
\text { endpoint } Y \text { of } \\
\text { line segment }\end{array}$ \\
\hline 1 & 1 & 3.902368613 & 31.66493389 & 17.13418358 & 91.78991061 & 3.634777623 & 23.10202219 & 4.169959604 & 40.22784559 \\
1 & 2 & 10.45834788 & 56.68469152 & 14.50432034 & 119.8759927 & 6.845869511 & 50.39630324 & 14.07082626 & 62.9730798 \\
1 & 3 & 13.26805329 & 71.66978699 & 15.48563651 & 108.1218602 & 10.85973437 & 64.31103475 & 15.6763722 & 79.02853924 \\
1 & 4 & 17.81710013 & 94.68261219 & 18.53345324 & 94.96974073 & 17.01432715 & 85.45072301 & 18.6198731 & 103.9145014 \\
$\vdots$ & $\vdots$ & $\vdots$ & $\vdots$ & $\vdots$ & $\vdots$ & $\vdots$ & $\vdots$ & $\vdots$ & $\vdots$ \\
97 & 79 & 133.5649822 & 127.8110631 & 15.18768713 & 117.7185016 & 130.0328734 & 121.0886627 & 137.0970909 & 134.5334636 \\
97 & 80 & 111.1190009 & 154.244909 & 13.81812699 & 76.65127289 & 109.5238551 & 160.9673095 & 112.7141468 & 147.5225086 \\
97 & 81 & 127.8680326 & 137.4958774 & 17.35616609 & 93.76403486 & 127.2983377 & 128.836514 & 128.4377276 & 146.1552407 \\
\hline
\end{tabular}

TABLe 3: Manual review of crack spacing.

\begin{tabular}{lccccccccccccccccccccc}
\hline Photo ID & $P 1$ & $P 2$ & $P 3$ & $P 4$ & $P 5$ & $P 6$ & $P 7$ & $P 8$ & $P 9$ & $P 10$ & $P 11$ & $P 12$ & $P 13$ & $P 14$ & $P 15$ & $P 16$ & $P 17$ & $P 18$ & $P 19$ & $P 20$ \\
\hline $\begin{array}{l}\text { Weighted } \\
\text { spacing of } \\
\text { joints } \\
(\mathrm{cm})\end{array}$ & 41.1 & 27.3 & 38.6 & 37.1 & 24.8 & 32.2 & 42.7 & 22.1 & 28.3 & 25.1 & 25.4 & 32.5 & 37.9 & 32.0 & 29.1 & 20.0 & 26.0 & 18.3 & 11.9 & 23.0 \\
\hline $\begin{array}{l}\text { Joint } \\
\text { spacing } \\
\text { checked } \\
\begin{array}{l}\text { manually } \\
(\mathrm{cm})\end{array}\end{array}$ & 38.7 & 26.4 & 33.9 & 38.6 & 29.1 & 35.6 & 39.1 & 18.9 & 25.3 & 28.4 & 29.5 & 31.7 & 39.8 & 28.2 & 28.9 & 17.6 & 27.7 & 20.3 & 13.6 & 25.4 \\
\hline $\begin{array}{l}\text { Error rate } \\
(\%)\end{array}$ & 6.22 & 3.52 & 14.00 & 3.80 & 14.71 & 9.45 & 9.15 & 12.42 & 11.83 & 11.59 & 13.90 & 2.37 & 4.80 & 13.52 & 0.58 & 13.46 & 6.09 & 9.91 & 12.45 & 9.63 \\
\hline
\end{tabular}

statistics in the following Equation [37], where $J_{v}$ is the joint number of rock mass volumes (bars $/ \mathrm{m}^{3}$ ). $N$ is the number of structural plane groups in the statistical region; $S_{i}$ refers to the number of structural planes of the $i$ th group along the normal direction per meter long. $S_{0}$ is the number of nongroup joints per cubic meter of rock mass. The $J_{v}$ value calculated by Direct Method should directly count the number of joints in unit volume rock mass:

$$
J_{v}=\sum_{i=1}^{n} S_{i}+S_{0}, \quad i=1, \ldots, n .
$$

Generally, when the joints are evenly distributed, $J_{v}$ is changed from one-dimensional (in the borehole or a single survey line) to a three-dimensional multiplicative coefficient $K=1.35 \sim 6.0$, and $J_{v}$ is changed from being two-dimensional (joint number per unit area) to three-dimensional. The coefficient $K$ should be $1.15 \sim 1.35$ [38]. In this paper, the two-dimensional $J_{v}$ can be obtained from the number of joints and the size of the photograph in a close-up photograph. Convert the two-dimensional coefficient to the three-dimensional coefficient, as shown in the following equation, where $K$ is the conversion factor; $n$ is the number of joints in a single photo; $A$ is the photo size $\left(\mathrm{cm}^{2}\right)$ :

$$
J_{v}=K \times \frac{n}{A}
$$

3.2.2. Rock Quality Index RQD. RQD (rock quality designation) was proposed and developed by Deere (1964) at the University of Illinois, USA. It is an internationally accepted method for identifying the quality of rock engineering and is a quantitative parameter reflecting the integrity of engineering rock mass [39]. The method uses the corrected core take-up rate of the borehole to evaluate the quality of the rock; that is, the diamond drill bit with a diameter of $75 \mathrm{~mm}$ and the doublelayer core tube are drilled in the rock, and the core is taken continuously, and the drill is taken back. In the core, the ratio of the sum of the lengths of the core segments greater than $10 \mathrm{~cm}$ in length to the return stroke is expressed as a percentage. Palmstrom [38] proposed three estimation methods of rock quality index RQD, namely, Farmer Joint Density Estimation Method, Volume Joint Counting Estimation Method, and Precision Line Estimation Method. In this paper, Volume Joint Counting Estimation Method is adopted. The calculation of RQD value is shown in te following equation; when $J_{v}<4.5$, $\mathrm{RQD}=100$; RQD is equal to 0 when $J_{v} \geq 35$ :

$$
\mathrm{RQD}=115-3.3 J_{v} \text {. }
$$

3.2.3. Rock Mass Integrity Index $K_{v}$. The rock mass integrity coefficient, also known as the fissure coefficient, indicates the integrity of the rock mass, which is the square of the ratio of the longitudinal wave velocity of the rock mass to the rock. The integrity factor can be determined by the dynamic method. The calculation method is shown in the following equation, where $K_{v}$ is the integrity coefficient of rock mass; $V_{\mathrm{pm}}$ is the longitudinal wave velocity of rock mass; $V_{\mathrm{pr}}$ is the longitudinal wave velocity of indoor rock (or rock block). Engineering Rock Mass Grading Standard (GB/T 
50218-2014) [37] indicates that when the measured value is unconditionally obtained, $K_{v}$ value can be determined by the rock mass volume joint number $J_{v}$ according to Table 4 :

$$
K_{v}=\left(\frac{V_{\mathrm{pm}}}{V_{\mathrm{pr}}}\right)^{2}
$$

3.3. Surrounding Rock Strength Stress Ratio. According to the specification, when the engineering rock mass has the initial stress state represented by the strength stress ratio, the influence of the initial stress state on the correction coefficient $K_{3}$ should be considered. According to the surrounding rock mass strength stress ratio, $K_{3}$ is selected to modify the basic quality index of rock mass BQ, as shown in Table 5 [37]. In the stability analysis of underground engineering structures such as roadways and stopes, the original rock stress is an initial stress boundary condition, and the original rock stress is the force source causing the deformation and destruction of underground engineering structures. The source of mine pressure is closely related to the original rock stress. Before calculating the stress distribution around any excavated rock mass, the stress state before excavation must be measured or estimated. The original rock stress is the sum of gravity stress and tectonic stress.

The mine completed the original rock stress measurement in 2011. According to the information provided by the metal mine, seven ground stress holes were arranged by the hollow inclusion strain gauge [40-44], and the hollow inclusion stress relief data collection was performed using YJL-16 type intelligent data static. The resistance strain gauge collects data every $3 \mathrm{~cm}$ when the hole stress is released, as shown in Figures 6 and 7. According to the data obtained by the measurement, the ground stress measurement results of each measuring point are as follows: (1) the maximum principal stress is located in the horizontal direction, and its value is 1.2 1.8 times of the dead weight stress; (2) the maximum horizontal principal stress $\left(\sigma_{h, \max }\right)$, minimum horizontal principal stress $\left(\sigma_{h, \min }\right)$, and vertical principal stress $\left(\sigma_{v}\right)$ all show approximately linear growth with the increase of depth. By using linear regression theory, the relationship between each principal stress and depth is shown in the following equations. The linear regression relationship between maximum horizontal principal stress, minimum horizontal principal stress, and vertical principal stress with depth is shown in Figure 8. The strength-stress ratio of surrounding rock can be calculated from the relationship between principal stress and depth and rock uniaxial compressive strength $R c$ :

$$
\begin{aligned}
\sigma_{h, \text { max }} & =0.06+0.047 \mathrm{H}, \\
\sigma_{h, \min } & =0.12+0.022 \mathrm{H}, \\
\sigma_{v} & =0.02+0.0278 \mathrm{H} .
\end{aligned}
$$

From the value of the stress measurement results, the distribution of the in situ stress field at the three horizontal measurement points in the mining area has the following laws: (1) the results of each measurement point have two principal stresses close to the horizontal direction and the angle between
TABLE 4: Correspondence between $J_{v}$ and $K_{v}$.

\begin{tabular}{lccccc}
\hline$J_{v}\left(\right.$ bar $\left./ \mathrm{m}^{3}\right)$ & $<3$ & $3 \sim 10$ & $10 \sim 20$ & $20 \sim 35$ & $\geq 35$ \\
\hline$K_{v}$ & $>0.75$ & $0.75 \sim 0.55$ & $0.55 \sim 0.35$ & $0.35 \sim 0.15$ & $\leq 0.15$ \\
\hline
\end{tabular}

TABLe 5: Effect of initial stress state on correction factor $K_{3}$.

\begin{tabular}{lccccc}
\hline $\begin{array}{l}\text { Surrounding rock } \\
\text { strength stress ratio } \\
\left(R_{c} / \sigma_{\text {max }}\right)\end{array}$ & $>550$ & $550 \sim 451$ & $450 \sim 351$ & $350 \sim 251$ & $\leq 250$ \\
\hline$<4$ & 1.0 & 1.0 & $1.0 \sim 1.5$ & $1.0 \sim 1.5$ & 1.0 \\
$4 \sim 7$ & 0.5 & 0.5 & 0.5 & $0.5 \sim 1.0$ & $0.5 \sim 1.0$ \\
\hline
\end{tabular}



FIGURE 6: $-455 \mathrm{~m}$ stress relief process curve of measuring point 7\# in the horizontal middle section.

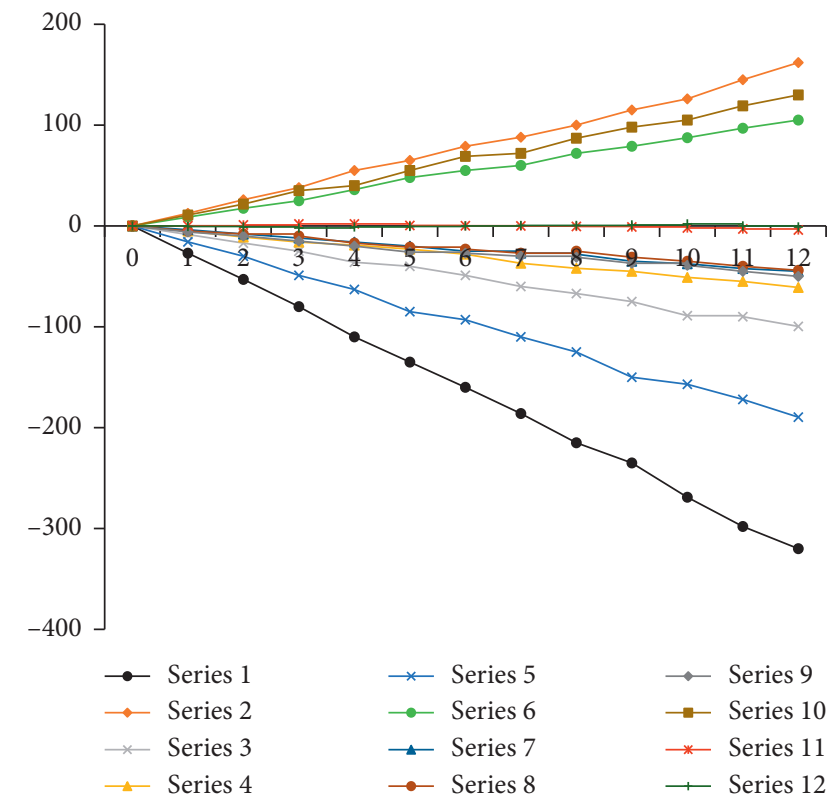

FIgURE 7: $-455 \mathrm{~m}$ horizontal middle section 7\# measuring point confining pressure constant curve. 


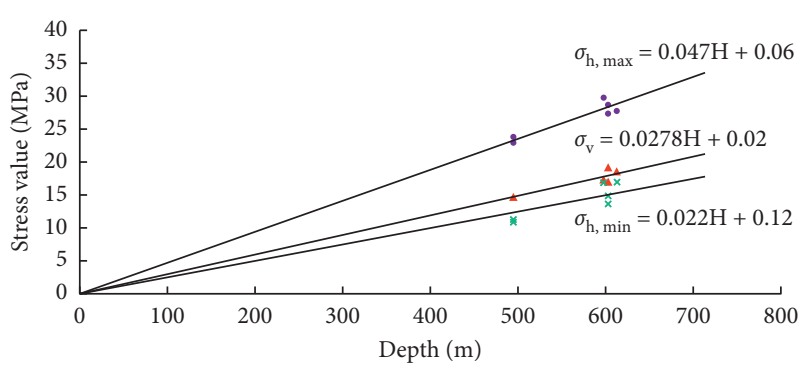

- Maximum principal stress

× Minor principal stress

$\triangle$ Vertical principal stress

FIgURE 8: Relationship of $\sigma_{h, \max }, \sigma_{h, \min }$, and $\sigma_{v}$ to depth.

the maximum principal stress and the horizontal plane. The average is $12^{\circ}$ and the maximum is $25^{\circ}$, indicating that the horizontal tectonic stress is the dominant stress; the direction of the intermediate principal stress is close to the vertical direction; (2) the maximum principal stress is located in the horizontal direction, and its value is 1.2-1.8 times the weight stress; (3) the direction of the maximum principal stress except for the $6 \#$ measuring point is in the northeast-southwest direction as a whole; the minimum principal stress is in the north-northwest direction, and the maximum horizontal principal stress is 1.7-2.2 times the minimum principal stress; (4) the vertical stress value is basically equal to or slightly greater than the weight of the upper strata; (5) the maximum horizontal principal stress $\left(\sigma_{h, \max }\right)$, the minimum horizontal principal stress $\left(\sigma_{h, \min }\right)$, and the vertical principal stress $\left(\sigma_{v}\right)$ all show an approximately linear growth relationship with the increase of depth. Using linear regression theory, the relationship between each principal stress and depth is obtained in (12) and (13). The regression coefficient in (12) is 0.0278 and the coefficient in the average bulk density of the overburden $(2.7-2.8) \times 104 \mathrm{~N} / \mathrm{m}^{3}$ is very close, reflecting the fact that the vertical stress is basically equal to or slightly greater than the self-weight stress.

3.4. Rock Mass Quality Classification. Rock mass quality classification is a comprehensive reflection of the characteristics of engineering rock mass. In engineering practice, the rock mass is generally classified according to various specifications, and then the bearing capacity and other parameters are selected according to the quality classification. Rock mass classification provides scientific reference for production optimization design, such as drilling, blasting, and support. The accuracy of rock mass classification is of great significance to rock mass engineering. The commonly used rock mass quality classification is based on RMR classification method and BQ classification method, etc. In this paper, combined with RMR method and BQ method, the rock mass around the mine level of $-540 \mathrm{~m}$ is, respectively, carried out.

RMR (rock mass rating) method was proposed by Bieniawski [45] in 1973 as a method to determine the quality level of rock mass, and it has been modified for 4 times successively, which is now based on the 1989 version [46]. The system considers the uniaxial compressive strength $(R 1)$ of the rock mass, the rock quality index RQD $(R 2)$, the structural plane spacing $(R 3)$, the structural surface condition $(R 4)$, the groundwater condition $(R 5)$, and the structural surface occurrence and engineering. The relationship of the trend (R6), a total of six indicators as basic parameters, and the main factors affecting the stability of the rock mass is scored, and the sum value is taken as the RMR value of the rock mass, as shown in

$$
\mathrm{RMR}=R 1+R 2+R 3+R 4+R 5+R 6 .
$$

Engineering Rock Mass Grading Standard (GB/T 50218-2014) [37] is the most commonly used rock mass quality evaluation method in China. This standard adopts the comprehensive index method composed of multiple parameters. Taking the quantitative indexes $R_{c}$ and $K_{v}$ of the two grading factors as parameters, the basic quality index of rock mass (BQ) is calculated according to the formula, and BQ is used as the quantitative index of the classification level, as shown in the following equation. When $R_{c}>90 K_{v}+30$, take $R_{c}=90 K_{v}+30$. When $K_{v}>0.04 R_{c}+0.4$, take $K_{v}=0.04 R_{c}+0.4$ :

$$
\mathrm{BQ}=100+3 R_{c}+250 K_{v} \text {. }
$$

In this paper, the self-programming process is used to process and calculate the above-mentioned indicators. According to the specification, the scores of 97 groups of data are given. After the BQ is modified according to the specifications, the underground engineering rock mass quality index [BQ] is obtained, and the BQ is calculated according to the maximum score of 100 . The value is approximately the same as the RMR score of the percentile system, and the average error rate is $8.26 \%$. The results are shown in Table 6. Among the 97 graded test sections, 20 of them had the same grade, with an agreement rate of $20.6 \%$, and 63 of them had a grade difference, accounting for $64.9 \%$.

According to the information in Table 5, the distribution statistics of the RMR values of 97 groups of data can be obtained. As shown in Figure 9, the level IV rock mass in the measurement block is the largest, accounting for $54.6 \%$, while the rest are level II and III rock mass, without any level I or $\mathrm{V}$.

Software has been developed to make the grading evaluation process automatic. Only the database files prepared in the early stage need to be updated, and then the rock mass quality rating results and distribution statistical charts at the sampling measuring points in the mine can be obtained through rapid computer calculation.

BQ and RMR classification methods are comprehensive consideration of various factors of rock mass, and there is a certain correlation between them in essence. In order to learn from the successful experience of foreign engineering design based on rock mass classification, it is necessary to establish the relationship between the basic quality index of national standard rock mass BQ and foreign classification. In 2001, Cai Bin et al. performed statistical analysis on the measured data of different engineering sites to establish the relationship between [BQ] (corrected value of BQ) and RMR [47]. In 2004, Jiang Ping analyzed the relationship between BQ and RMR by combining 54 measured values of highway 









FIGURE 9: Rock mass RMR distribution statistics at the sampling point.

slope in Yixing section of Ninghang expressway [48]. In 2009, Yan combined other materials with the actual measurement data of the surrounding rock of the underground cavern of Dagangshan Hydropower Station, and the relationship between the BQ correction value and RMR and $Q$ was obtained [49]. In this paper, 97 groups of BQ and RMR values and [BQ] and RMR values were linearly and exponentially fitted respectively, and the correlation between BQ and RMR and $[\mathrm{BQ}]$ and RMR was established. The results are shown in Figure 10.

The results show that there is a good correlation between $\mathrm{BQ}$ and RMR and [BQ] and RMR, and their linear fitting relationship is more appropriate than the exponential fitting relationship. The rock mass quality level is roughly in the range of II IV, and the correlation between the $\mathrm{BQ} \longrightarrow \mathrm{RMR}, \mathrm{RMR} \longrightarrow \mathrm{BQ}$, and other indicators can be converted.

\section{3D Visualization of Engineering Rock Mass Quality Indicators}

Through the above methods and steps, the indicators and conclusions for evaluating rock mass quality can be obtained automatically according to the collection of rock mass information to be evaluated and the related processing of computer programs. In order to meet the convenience of the project, a three-dimensional rock mass model is established and interpolated to give the rock mass quality evaluation index, so that the rock mass quality information can be obtained intuitively and conveniently. By directly or sliceobserving the assigned three-dimensional rock mass model, it is possible to understand and predict the quality of the rock mass near a certain coordinate, which is of great significance for judging the safety and construction feasibility of mines, tunnels, slopes, and other projects.

In the actual project, the data collected by the drilling data and the trench data are limited. To obtain the internal information of the rock mass, a reasonable geological variable estimation method must be used. In the field of geology, rock mass quality indicators and deposit grades have a certain correlation in space; that is, variables within a certain range have mutual influences. The power-inverse ratio method is one of the most commonly used spatial interpolation methods. When calculating the value of an interpolation point, according to the principle that the larger the distance is, the larger the weight value is, the linear weighting of several adjacent points is used to fit the value of the estimated point. Assume that the point to be estimated in the three-dimensional space is $P$ point, the coordinates $\left(x_{p}, y_{p}, z_{p}\right)$, and a series of discrete points around it are unevenly distributed sample points, coordinates $\left(x_{i}, y_{i}, z_{i}\right)$, sample point attribute values $P_{i}(i=1,2, \ldots n)$, the distance between the point to be estimated and the sample point is recorded as $d_{i}$, and the attribute value $P$ of the distance to be estimated by the power-inverse ratio method is as shown in the following equation [50]. In the formula, $m$ is the power value of the power-inverse ratio method. The larger the power, the greater the weight of the nearest point to the estimated point. In this paper, the power is 2 :

$$
P=\frac{\sum_{i=1}^{n}\left(P_{i} /\left[d_{i}(x, y, z)\right]^{m}\right)}{\sum_{i=1}^{n}\left(1 /\left[d_{i}(x, y, z)\right]^{m}\right)} .
$$

In this paper, RMR value is selected as attribute value to get rock mass grade distribution at $-540 \mathrm{~m}$ level. According to the horizontal geological plane map of each level, the boundary information of rock mass can be obtained, and the solid model of rock mass can be established preliminarily by importing the boundary information into the 3DMine software as a constraint condition, as shown in Figure 11.

Combining the acquired RMR values with the photo field locations in Table 1 yields a set of $(x, y, z$, RMR) data sets that will be used as sample points for block model assignment. Firstly, a solid model of the cube containing the estimated area was established to observe the rock mass distribution near the level of $-540 \mathrm{~m}$ more intuitively [51-55]. The $z$ direction of the cube was $-560 \sim-450 \mathrm{~m}$, and the $x$ and $y$ directions were $529500 \sim 532099 \mathrm{~m}$ and $3431599 \sim 3433849 \mathrm{~m}$, respectively; Secondly, the solid model is converted into a block model. The size of the block is $10 \mathrm{~m} \times 10 \mathrm{~m} \times 10 \mathrm{~m}$, and the new block attribute RMR is created. Finally, using the power-inverse ratio method to assign values to the block based on the sample point data, a block model with an RMR attribute value for each block is obtained. The rock mass distribution of $-560 \sim-450 \mathrm{~m}$ can be visually observed, as shown in Figure 12. Slice the block with plane $Z=-540$ to obtain the rock mass grading distribution at the level of $-540 \mathrm{~m}$, as shown in Figure 13 . Taking the rock mass near the level of $-540 \mathrm{~m}$ as the research object, the comprehensive research on the threedimensional visual classification of rock mass quality can provide scientific reference for the design optimization of rock drilling, blasting, and support and reduce the production cost. 


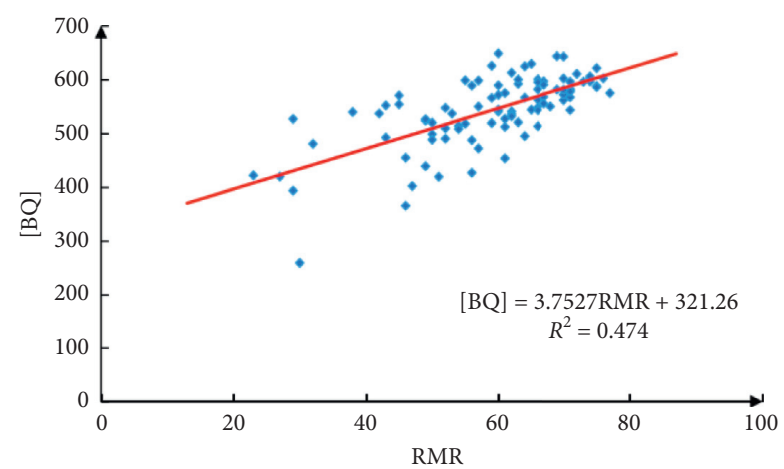

(a)

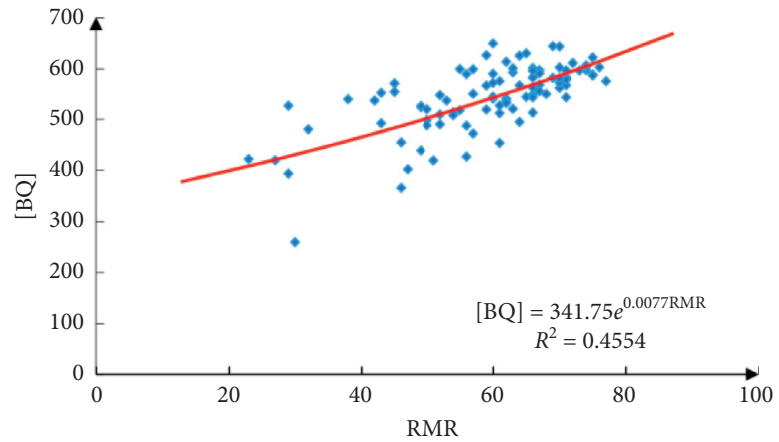

(c)

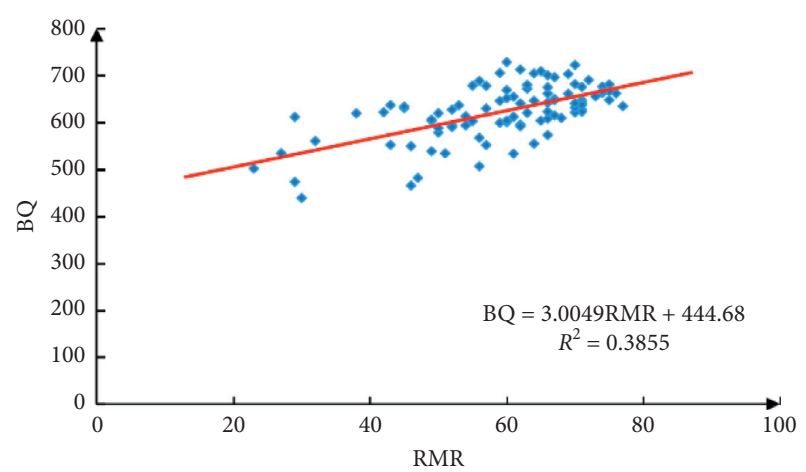

(b)

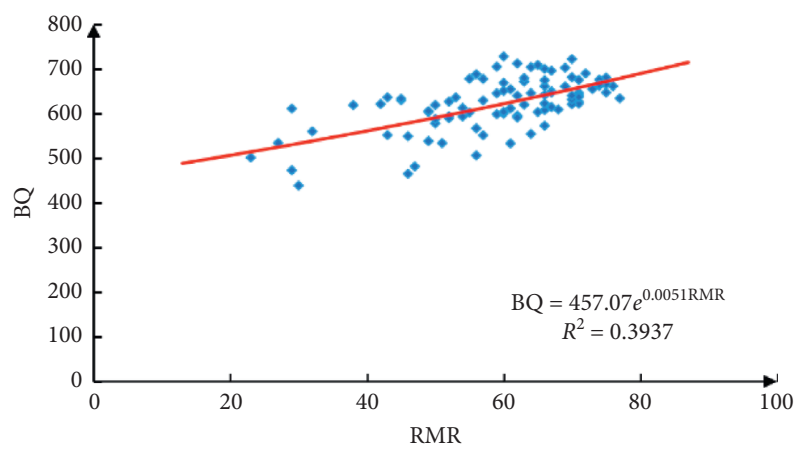

(d)

FIGURE 10: Fitting curve of [BQ]/BQ and RMR, (a) RMR-[BQ] linear fitting straight line, (b) RMR-BQ linear fitting straight line, (c) RMR$[B Q]$ exponential fitting curve, and (d) RMR-BQ index fitting curve.



Monzoporphyry

Figure 11: Ore body and rock mass model.

The classification method and visualization system proposed in this paper have been automated in most aspects. Simple updates to data can be made at any time, being convenient and fast. It takes only a few tens of minutes to input the data to the map of the status quo of the rock mass distribution at all levels. After obtaining the distribution diagram of each level rock mass class, the support design,
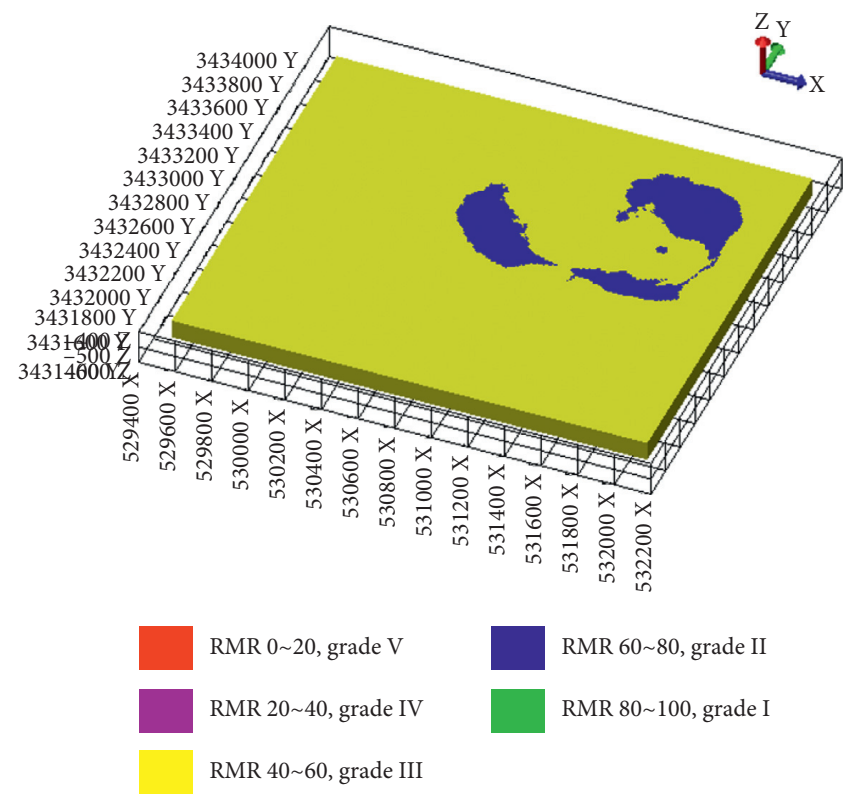

FIGURE 12: $-560 \sim-450 \mathrm{~m}$ RMR index rock mass classification 3D model.

blasting scheme setting, and drilling scheme optimization can be carried out as a whole for different levels of rock mass regions. 


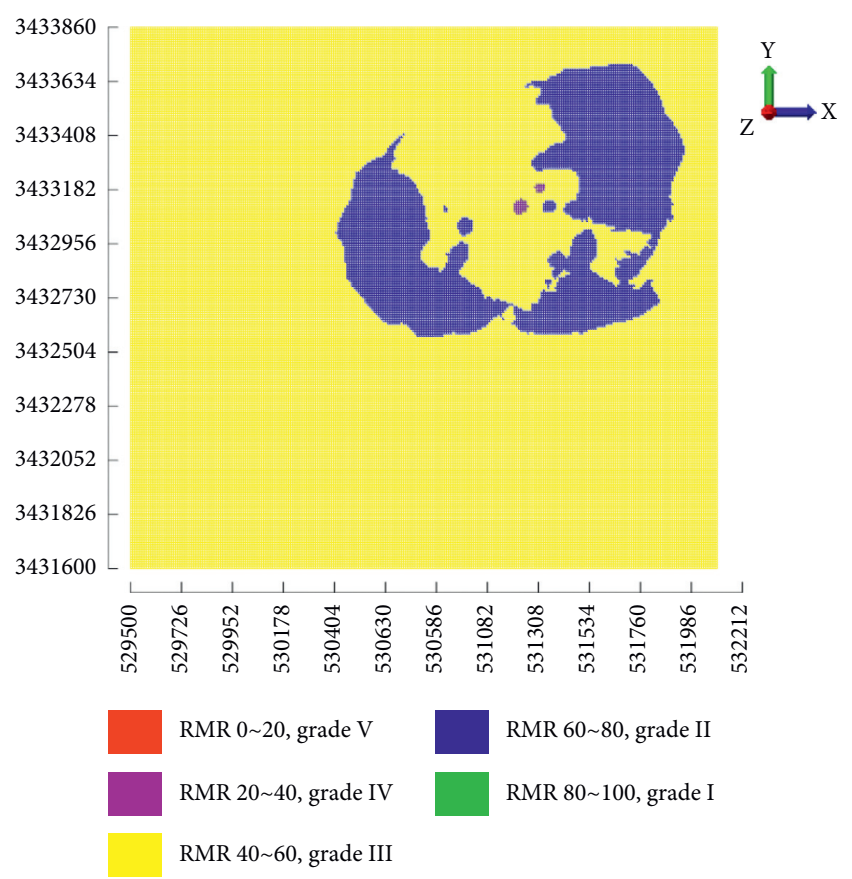

FIGURE 13: Current status map of horizontal grading distribution of $-540 \mathrm{~m}$ horizontal rock mass.

\section{Conclusion}

Put forward the optimization of traditional rock mass quality evaluation method based on $3 \mathrm{D}$ visualization of rock mass quality evaluation method of close shot photography and system, solve the traditional method of adverse operating environment manual labor intensity big, long time consuming, and accomplish three-dimensional visual; the rock mass classification problem uncovered rock mass quality classification valuation grade and achieved good effect. The main conclusions are as follows:

(1) A method for acquiring key feature parameters of joints based on close-range photography is proposed. The method extracts key characteristic parameters such as length, inclination, centroid position, spacing, and quantity of cracks in close-range photography photos by self-programming.

(2) Based on various literature achievements related to RMR method and BQ method as well as the research and analysis of 97 groups of data measured in a mine field in south China, the engineering practice effect of RMR method and BQ method and their correlation are studied and summarized. The research shows that the two rock mass classification methods have perfect engineering adaptability and correlation.

(3) A 3D visualization method for rock mass quality classification is presented. The method establishes a three-dimensional block model suitable for a particular mine based on entity model such as ore bodies and surrounding rocks. The rock mass quality index (RMR/BQ) of each survey point was combined with the field coordinates to create the sample points of rock mass quality index of the area to be estimated. The three-dimensional block model is endowed through the power-inverse ratio method to get the three-dimensional rock mass classification model of mine, and the three-dimensional visualization of rock mass quality classification is finally realized.

In conclusion, the $3 \mathrm{D}$ visualization rock mass quality evaluation method and system based on photographing technology have great application advantages, such as saving time, improving the evaluation accuracy by weakening manual intervention, reducing the engineering economic cost, and ensuring the safety of human work. It provides a new idea for modern rock mass quality evaluation and monitoring and is worth popularizing.

\section{Data Availability}

All data generated or analyzed during this study are included within this article.

\section{Conflicts of Interest}

The authors declare no conflicts of interest.

\section{Acknowledgments}

The authors gratefully acknowledge support for this research from the National Natural Science Foundation of China (51874112, 51774107, and 42077249) and the Open Program of State Key Laboratory of Explosion Science and Technology (Beijing Institute of Technology) (KFJJ20).

\section{References}

[1] D. Gu, Foundation of Rock Mass Engineering Geomechanics, Science Press, Beijing, China, 1979.

[2] W. Mingdong, F. Dai, N. Xu, T. Zhao, and Y. Liu, "An experimental and theoretical assessment of semi-circular bend specimens with chevron and straight-through notches for mode I fracture toughness testing of rocks," International Journal of Rock Mechanics and Mining Sciences, vol. 99, pp. 28-38, 2017.

[3] F. Peng, F. Dai, Y. Liu, N. Xu, and P. Fan, "Effects of coupled static and dynamic strain rates on the mechanical behaviors of rock-like specimens containing preexisting fissures under uniaxial compression," Canadian Geotechnical Journal, vol. 55, no. 5, pp. 640-652, 2018.

[4] W. Mingdong, F. Dai, N. Xu, Y. Liu, and T. Zhao, "A novel chevron notched short rod bend method for measuring the mode I fracture toughness of rocks," Engineering Fracture Mechanics, vol. 190, pp. 1-15, 2018.

[5] W. Mingdong, F. Dai, N. Xu, T. Zhao, and K. Xia, "Experimental and numerical study on the fracture process zone and fracture toughness determination for ISRM-suggested semicircular bend rock specimen," Engineering Fracture Mechanics, vol. 154, pp. 43-56, 2016.

[6] P. H. S. W. Kulatilake and T. H. Wu, "Estimation of mean trace length of discontinuities," Rock Mechanics and Rock Engineering, vol. 17, no. 4, p. 215, 1984. 
[7] J. Hu, B. Yu, and L. Guo, "Using the geological structure survey method to determine the direction of the minimum resistance line of fractured rock mass blasting," China Mining, vol. 21, no. 9, pp. 122-124, 2012.

[8] C. Chen and G. Wang, "Discussion on the correlation of various rock mass quality evaluation methods," Journal of Rock Mechanics and Engineering, vol. 21, no. 12, pp. 18941900, 2002.

[9] D. Zhang and S. Bai, "Measurement method of joint fracture surface opening in rock mass," China Testing Technology, vol. 29, no. 3, pp. 33-34, 2003.

[10] G. Lei, C. Yang, G. Wang et al., "Geometrical characteristics and evaluation of rock mass joints in the new site of Beishan preselected area," Chinese Journal of Rock Mechanics and Engineering, vol. 35, no. 5, pp. 896-905, 2016.

[11] J. Zhang, Y. Xing, and L. Zheng, "Research on fracture identification using artificial intelligence technology," Logging Technology, vol. 29, no. 1, pp. 52-55, 2005.

[12] C. Wang, P. Hu, and W. Sun, "Rock mass integrity evaluation method based on borehole camera technology," Rock and Soil Mechanics, vol. 31, no. 4, pp. 1326-1330, 2010.

[13] D. M. Ross-Brown and K. B. Atkinson, "Terrestrial photogrammetry in open-pits: 1-descripion and use of the Phototheodolite in mine surveying," Instution of Mining \& Metallurgy, vol. 81, no. 1, pp. 7-11, 1972.

[14] S. Tian, X. Ge, and Z. Tu, "Experimental study on digital closerange photogrammetry of tunnel and underground space structure deformation," Chinese Journal of Rock Mechanics and Engineering, vol. 25, no. 7, pp. 1309-1315, 2006.

[15] F. Wang, J. Chen, X. Fu et al., "Research on acquiring geometric information of rock mass structural plane based on VirtuoZo," Chinese Journal of Rock Mechanics and Engineering, vol. 27, no. 1, pp. 169-175, 2008.

[16] C. Zhou, H. Zhu, and W. Zhao, "Non-contact measurement method for the appearance of rock mass structural plane with binocular system," Chinese Journal of Rock Mechanics and Engineering, vol. 29, no. 1, pp. 111-117, 2010.

[17] Y. Wang, S. Wang, M. Guo et al., "Fast digital recognition and stability analysis of joint information on tunnel face," Chinese Journal of Geotechnical Engineering, vol. 33, no. 11, pp. 1734-1739, 2011.

[18] Y. Liu, F. Dai, L. Dong, N. Xu, and P. Feng, "Experimental investigation on the fatigue mechanical properties of intermittently jointed rock models under cyclic uniaxial compression with different loading parameters," Rock Mechanics and Rock Engineering, vol. 51, no. 1, pp. 47-68, 2018.

[19] Y. Liu, F. Dai, P. Fan, N. Xu, and L. Dong, "Experimental investigation of the influence of joint geometric configurations on the mechanical properties of intermittent jointed rock models under cyclic uniaxial compression," Rock Mechanics and Rock Engineering, vol. 50, no. 6, pp. 1453-1471, 2017.

[20] Z. Wu, D. Nie, X. Li et al., "Research on acquisition and processing of rock mass structure information based on digital image," Chinese Journal of Rock Mechanics and Engineering, vol. 22, no. S2, pp. 2568-2571, 2003.

[21] L. Fan and L. Ning, "Research on intelligent interpretation method of rock mass fracture image based on pattern recognition technology," Progress in Natural Science, vol. 14, no. 2, pp. 236-241, 2004.

[22] S. Li, H. Liu, L. Li et al., "Quantitative characterization method and engineering application of rock mass structure based on digital image," Journal of Rock Mechanics and Engineering, vol. 36, no. 1, pp. 1-9, 2017.
[23] F. J. Galdames, C. A. Perez, P. A. Estévez, and M. Adams, "Classification of rock lithology by laser range 3D and color images," International Journal of Mineral Processing, vol. 160, pp. 47-57, 2017.

[24] W. Tan, Y. Wu, J. Liu et al., "Improvement of Q system for deep rock mass quality classification," China Mining, vol. 29, no. 2, pp. 161-165, 2020.

[25] L. Wang, J. Li, J. Li et al., "Correction and engineering application of RMR evaluation system," Chinese Journal of Rock Mechanics and Engineering, vol. 32, no. S2, pp. 3309-3316, 2013.

[26] Q. Chen, T. Yin, and Y. Gao, "Study on the three-dimensional division method of the homogeneous region of the fissured rock mass structure in underground mines," Rock and Soil Mechanics, vol. 40, no. 8, pp. 3181-3188, 2019.

[27] Y. Su and M. Ning, "Method for judging surrounding rock grades based on maximum interval classifier," Chinese Journal of Underground Space and Engineering, vol. 28, no. 5, pp. 803-805, 2008.

[28] Y. Cong, H. Guo, Y. Zheng et al., "Research on surrounding rock classification method for rock subway engineering," Modern Tunnelling Technology, vol. 53, no. 3, pp. 33-41, 2016.

[29] M. A. Aguilar, F. J. Aguilar, and F. Agüera, "Mapping small areas using a low-cost close range photogrammetric software package with aerial photography," The Photogrammetric Record, vol. 20, no. 112, p. 16, 2005.

[30] S. Martínez, J. Ortiz, M. L. Gil, and M. T. Rego, "Recording complex structures using close range photogrammetry: the cathedral of santiago de compostela," The Photogrammetric Record, vol. 28, no. 144, pp. 375-395, 2013.

[31] S. Huang, Z. Zhang, T. Ke, M. Tang, and X. Xu, "Scanning photogrammetry for measuring large targets in close range," Remote Sensing, vol. 7, no. 8, pp. 10042-10077, 2015.

[32] S. K. Ghosh, "A close-range photogrammetric system for 3-D measurements and perspective diagramming in biomechanics," Journal of Biomechanics, vol. 16, no. 8, pp. 667-674, 1983.

[33] D. C. Brown, "Unflatness of plates as a source of systematic error in close-range photogrammetry," Photogrammetria, vol. 40, no. 4, pp. 343-363, 1986.

[34] S. S. Kang, H. Y. Kim, and B. A. Jang, "Correlation of in situ modulus of deformation with degree of weathering, RMR and Q-system," Environmental Earth Sciences, vol. 69, no. 8, 2012.

[35] S. Y. Choi and H. D. Park, "Comparison among different criteria of RMR and Q-system for rock mass classification for tunnelling in Korea," Tunnelling and Underground Space Technology, vol. 17, no. 4, pp. 391-401, 2002.

[36] A. Laderian and M. A. Abaspoor, "The correlation between RMR and Q systems in parts of Iran," Tunnelling \& Underground Space Technology Incorporating Trenchless Technology Research, vol. 27, no. 1, p. 0, 2012.

[37] GB/T 50218-2014, Engineering Rock Mass Grading Standard, China Planning Press, Beijing, China, 2015.

[38] A. Palmstrom, "Measurements of and correlations between block size and rock quality designation (RQD)," Tunnelling and Underground Space Technology, vol. 20, no. 4, pp. 362377, 2005.

[39] G. L. Xu, "Estimation method of rock quality index RQD," Hydrogeology \& Engineering Geology, vol. 6, pp. 43-45, 1991.

[40] B. Amadei, "In situ stress measurements in anisotropic rock," International Journal of Rock Mechanics and Mining Sciences \& Geomechanics Abstracts, vol. 21, no. 6, pp. 327-338, 1984.

[41] X. Yang, J. Pang, H. Lou, and L. Fan, "Characteristics of in situ stress field at Qingshui coal mine," International Journal of 
Mining Science and Technology, vol. 25, no. 3, pp. 497-501, 2015.

[42] F. Dai, B. Li, N. Xu et al., "Deformation forecasting and stability analysis of large-scale underground powerhouse caverns from microseismic monitoring," International Journal of Rock Mechanics and Mining Sciences, vol. 86, pp. 269-281, 2019.

[43] A. Li, Y. Liu, F. Dai, K. Liu, and M. Wei, "Continuum analysis of the structurally controlled displacements for large-scale underground caverns in bedded rock masses," Tunnelling and Underground Space Technology, vol. 97, Article ID 103288, 2020.

[44] Y. Wang, H. Zhang, H. Lin, Y. Zhao, and Y. Liu, "Fracture behaviour of central-flawed rock plate under uniaxial compression," Theoretical and Applied Fracture Mechanics, vol. 106, Article ID 102503, 2020.

[45] Z. T. Bieniaski, "Engineering classification of jointed rock masses," Transaction of the South African Institution of Civil Engineering, vol. 15, no. 12, pp. 335-344, 1973.

[46] Z. T. Bieniawski, Engineering Rock Mass Classification, pp. 180-250, Science Press, New York, NY, USA, 1989.

[47] B. Cai, Y. Yu, and X. Wu, "Relationship between "classification standard of engineering rock mass" and Q classification and RMR classification and deformation parameter estimation," Journal of Rock Mechanics and Engineering, vol. 20, no. z1, pp. 1677-1679, 2001.

[48] C. Wang, D. Li, and W. Zhao, "Discussion on the overall stability of the high slope of Lanyoushan deep road cutting in Yixing, Nanjing-Hangzhou expressway," Journal of Disaster Prevention and Mitigation Engineering, vol. 4, pp. 417-422, 2004.

[49] T. Yan, X. Wu, and L. Wu, "Correlation study and engineering application of the classification of surrounding rocks in underground caverns," Chinese Journal of Underground Space and Engineering, vol. 5, no. 3, pp. 41-47, 2009.

[50] P. Duan, Y. H. Sheng, J. Li, L. V. Haiyang, and S. Zhang, "Adaptive IDW interpolation method and its application in air temperature field," Geographical Research, vol. 33, no. 8, pp. 1417-1426, 2014.

[51] F. Wu, R. Gao, Q. Zou, J. Chen, W. Liu, and K. Peng, "Longterm strength determination and nonlinear creep damage constitutive model of salt rock based on multistage creep test: implications for underground natural gas storage in salt cavern," Energy Science \& Engineering, vol. 8, pp. 1592-1603, 2020.

[52] H. Lin, H. Yang, Y. Wang, Y. Zhao, and R. Cao, "Determination of the stress field and crack initiation angle of an open flaw tip under uniaxial compression," Theoretical and Applied Fracture Mechanics, vol. 104, Article ID 102358, 2019.

[53] H. Yuan, C. Chen, Z. He, and Y. Wang, "Numerical simulation of fluid-solid coupling in surrounding rock for river stope mining," Shock and Vibration, vol. 2020, no. 4, 11 pages, Article ID 9786182, 2020.

[54] Y. Zhao, Y. Wang, W. Wang et al., "Modeling of rheological fracture behavior of rock cracks subjected to hydraulic pressure and far field stresses," Theoretical \& Applied Fracture Mechanics, vol. 101, 2019.

[55] B. X. Yuan, L. Xiong, L. Zhai et al., "Transparent synthetic soil and its application in modeling of soil-structure interaction using optical system," Frontiers in Earth Science, vol. 7, p. 276, 2019. 